\title{
Incidence of Nephrotoxicity Associated with Intravenous Colistimethate Sodium Administration for the Treatment of Multidrug-resistant Gram- negative Bacterial Infections
}

Svetlana Sadyrbaeva-Dolgova ( $\sim$ sadyrbaeva@gmail.com )

Hospital Universitario Virgen de las Nieves

Ricardo García-Fumero

Hospital Universitario Virgen de las Nieves

Alberto Jimenez-Morales

Hospital Universitario Virgen de las Nieves

Juan Pasquau

Hospital Universitario Virgen de las Nieves

Carmen Hidalgo-Tenorio

Hospital Universitario Virgen de las Nieves

\section{Research Article}

Keywords:

Posted Date: February 15th, 2022

DOI: https://doi.org/10.21203/rs.3.rs-1246386/v1

License: (a) (i) This work is licensed under a Creative Commons Attribution 4.0 International License.

Read Full License 


\section{Abstract}

Colistimethate sodium (CMS) is the inactive prodrug of colistin, CMS has a narrow antibacterial spectrum with concentration-dependent bactericidal activity against multidrug-resistant gram-negative bacteria, including $P$. aeruginosa and Acinetobacter baumannii. This study aimed to analyze potential correlations between clinical features and the development of CMS-induced nephrotoxicity. This retrospective cohort study was conducted in a tertiary-care university hospital between 1 January 2015 and 31 December 2019. A total of 163 patients received CMS therapy. 75 patients (46\%) developed nephrotoxicity attributable to colistin treatment, although only 14 patients (8.6\%) discontinued treatment for this reason. $95.7 \%$ of CMS were prescribed as target therapy. Acinetobacter baumanii spp. was the most commonly identified pathogen (72.4\%) followed by Pseudomonas aeruginosa (19.6\%). Several risk factors associated with nephrotoxicity were identified, among these were Charlson Index (OR 1.29, 95\% $\mathrm{Cl} 1.02-$ 1.62; $\mathrm{p}=0.032)$; admission to the ICU $(\mathrm{OR} 4.25,95 \% \mathrm{Cl} 1.63-11.07, \mathrm{p}=0.003)$ and cumulative dose per patient (OR 1.03, 95\% Cl 1.01-1.05, p = 0.003). In terms of in-hospital mortality, risk factors were male sex (OR 2.43, 95\% Cl 1.06-5.56, $\mathrm{p}=0.035)$; age (OR 1.03, 95\% Cl 1.01-1.05, $\mathrm{p}=0.043)$ and higher maintenance doses $(\mathrm{OR} 1.21,95 \% \mathrm{Cl} 1.03-1.43, \mathrm{p}=0.023)$. Nephrotoxicity due to $\mathrm{CMS}$ treatment was not related to mortality $(\mathrm{OR} 1.42,95 \% \mathrm{Cl} 0.68-2.99, \mathrm{p}=0.351)$. In conclusion, it was shown once again that CMS is a drug with a high incidence of nephrotoxicity. Its complex management, administering the loading dose and monitoring creatinine at least every 48 hours, with consequent adjustment of the maintenance dosage, leads to a high percentage of inappropriate use.

\section{Introduction}

Severe nosocomial infections due to multidrug-resistant gram-negative bacteria (MDR-GNB) are deemed to be of high morbidity and mortality. The emergence of highly resistant gram-negative bacteria, in particular carbapenem-resistant Acinetobacter baumanii (CRAB) strains, multidrug-resistant Pseudomonas aeruginosa and carbapenem-resistant Klebsiella species, and the lack of effective antimicrobials, have led to reuse polymyxins, antibiotics available since 1950 but abandoned owing to their nephrotoxicity.

Colistin E is a polypeptide belonging to the polymyxin family, produced by Bacillus polymyxa subspecies colistinus ${ }^{1}$. Colistin's structure includes a polycationic peptide ring composed of 10 amino acids and a hydrophobic fatty acid tail ${ }^{2}$. It consists of at least 30 components, the 2 major ones being colistin $A$ and colistin $\mathrm{B}^{3}$.

Colistimethate sodium (CMS) is the inactive prodrug of colistin, a polymyxin that can be administered parenterally or by inhalation. CMS undergoes a rapid hydrolysis to methanesulfonated derivatives and to colistin. It is shown that colistin concentrations increase slowly after CMS administration in critically ill patients and it takes 2 days to reach steady state, suggesting the benefits of initiating treatment with a loading dose. ${ }^{4,5}$ 
CMS has a narrow antibacterial spectrum with concentration-dependent bactericidal activity against MDR-GNB, including $P$. aeruginosa and Acinetobacter baumannii. The mechanism of action of CMS involves interaction between the polycationic portion and the anionic portion of lipopolysaccharides (LPS) that compound the outer membrane, disrupting the outer membrane of gram-negative bacteria and providing bactericidal activity and probable enhancement of the activity of other antimicrobials ${ }^{6}$. Numerous antibiotics have shown synergistic activity with colistin in vitro; the most studied are rifampicin and imipenem, but also ceftazidime $e^{7,8}$.

The most common adverse reaction of CMS is nephrotoxicity and neurotoxicity. Nephrotoxicity usually occurs within a median of 2.5 to 10 days of therapy ${ }^{9-11}$ and renal function usually returns to normal within 3 to 9 weeks after treatment discontinuation ${ }^{12}$. Colistin induces tubular damage by increasing the membrane permeability of epithelial cells, which increases influx of cations, anions and water, leading to leakage of contents and cell death. The proposed mechanism is related to its mechanism of action against gram-negative bacteria ${ }^{9}$ and has shown a dose-dependent effect ${ }^{11,13}$. Given that nephrotoxicity is a well-known predictor of mortality ${ }^{14}$, it has been a common measurement during CMS therapy. However, the incidence of renal function alterations in this context is not well-established yet as many unexplored risk factors might be involved. It is clear that an urgent strategy to properly use CMS therapy against MDR-GNB is needed, as the incidence of colistin-resistant gram-negative bacteria, especially Acinetobacter spp., is increasing ${ }^{15}$. However, CMS therapy may still be an option for treating colistinresistant $C R A B$ infections ${ }^{16}$, increasing interest in studying the use of this valuable antimicrobial in daily practice.

Unfortunately, it is difficult to implement a patient-based approach to select the most appropriate antimicrobial therapy against these microorganisms. Interpatient variability is extensive even at a given creatinine clearance ${ }^{13}$, but minimizing it is crucial to enhance survival by reducing CMS-associated nephrotoxicity. This study aimed to analyze potential correlations between clinical features and the development of CMS-induced nephrotoxicity. Results may provide a more thorough understanding of that interpatient variability to avoid CMS misuse.

\section{Materials And Methods}

This retrospective cohort study was conducted in an 800-bed tertiary university hospital in Spain between 1 January 2015 and 31 December 2019.

All patients enrolled in this study ( $\geq 18$ y.o.) have received intravenous CMS for at least 48 hours.Clinical data were gathered using the hospital electronic medical records, which contain demographic, microbiological and prescription information. Demographic and clinical characteristics of patients, including age, sex, and baseline Charlson Comorbidity Index score were included. In relation to antibiotic treatment, data were gathered related to colistin loading dose and duration, concomitant use of antibiotic, infection sites and organisms with susceptibility. Also, baseline, peak creatinine and glomerular filtration 
(CKD-EPI) during colistin therapy, albumin, hemoglobin and leukocytes were collected. Only one treatment per patient and parenteral administration of the treatment were considered in the analysis; CMS administered by inhalation were excluded from the analysis.

Available colistin in our hospital is labelled GES ${ }^{\circledR}$ and is equivalent 1.000.000 $\mathrm{UI}(1 \mathrm{MU})$ of CMS is equal to $80 \mathrm{mg}$ of CMS or $34 \mathrm{mg}$ of colistin base activity (CBA). Therefore, the dose of $9 \mathrm{MU}$ is equal to $300 \mathrm{mg}$ and of $4.5 \mathrm{MU}$ is equal to $150 \mathrm{mg}$ of CBA.

The main outcome variables were: all-cause in-hospital mortality rate, efficacy based on clinical and microbiological response to the treatment, and length of current hospital stays. Clinical success was defined as the resolution of symptoms and signs of infection; microbiological cure as the eradication of MDR-GNB isolates on follow-up cultures, and failure as the persistence or worsening of symptoms and "escalating" therapy with additional antimicrobial agents for this infection.

Nephrotoxicity was stablished following the Kidney Disease Improving Global Outcomes (KDIGO) classification, creatinine elevation of $\geq 0.3 \mathrm{mg} / \mathrm{dL}$ in 48 hours or $\geq 1.5$ times baseline creatinine in an interval of up to 7 days ${ }^{17}$.

Appropriate CMS prescription was determined as administration of a loading dose of 9 million units (MU) followed by a maintenance dose of $4.5 \mathrm{MU}$ administered every 12 hours or $3 \mathrm{MU}$ every 8 hours. In patients with moderate to severe renal impairment after a loading dose of $9 \mathrm{MU}$, maintenance doses were adjusted according to CKD-EPI clearance estimates.

Combination therapy was considered when both antimicrobials were active against gram-negative microorganisms.

This study was approved by the local ethics committees (Comité de Ética de la Investigación (CEI/CEIM) de la Provincia de Granada) and the requirement for informed consent was waived for performing this study. Data collection was complied with the Helsinki declaration principles and biomedical research legislation (Law 3/2018, December 5).

All data generated or analyzed during this study are included in this published article (and its supplementary information files).

Statistical analysis:

Means, standard deviations, medians, and interquartile range were calculated for quantitative variables, and absolute and relative frequencies for qualitative variables. Relations among qualitative variables were analyzed using Pearson's or Fisher's chi-square test, while quantitative variables with non-normal distribution (Kolmogorov-Smirnov test) were analyzed with the non-parametric Mann-Whitney test.

A multivariate logistic regression model was constructed using backward stepwise selection considering entry criteria of $p \leq 0.05$ and exit criteria of $p>0.25$. All variables that showed statistical significance in 
bivariate analysis or were otherwise considered relevant were included. Results with $p \leq 0.05$ were considered statistically significant. Data management and analysis were performed using IBM SPSS Statistics 19 software.

\section{Results}

1. Descriptive analysis of the cohort

The study included 163 patients with CMS prescriptions over 5 years. The mean age was 66 years, and $71.2 \%$ were male.

At the time of CMS initiation, almost half of the patients were admitted to the Intensive Care Unit ICU (42.3\%). The median basal glomerular filtration rate estimated according to CKD-EPI was 92.2 $\mathrm{ml} / \mathrm{min} / 1.73 \mathrm{~m} 2$. The most frequent infection where CMS was prescribed was lower respiratory tract infection $(41.7 \%)$ followed by urinary tract infection $(22.7 \%)$ and others. $17.2 \%$ of all infections were associated with bacteremia.

Other characteristics of the patients are shown in Table1.

Regarding CMS prescriptions, $95.7 \%$ were prescribed as target therapy. Most of them given in combination therapy (64.4\%) with one or two antimicrobials against gram-negative pathogens, $51.5 \%$ and $12.9 \%$ respectively. The antibiotics mainly used in combination therapy were carbapenems (34.0\%) and tigecycline (24.0\%). Thirty-five patients (24.5\%) received a loading dose. The CMS prescriptions adjusted following variation of serum creatinine were $28.2 \%$. Hence, CMS prescriptions were appropriate for 25 patients (15.3\%). The median duration of CMS treatment was 10 days (IQR: $6-14$ ) and the median cumulative dose per patient was 63MU (IQR: 36-108).

Acinetobacter baumanii spp. was the most commonly identified pathogen $(72.4 \%)$ followed by Pseudomonas aeruginosa (19.6\%), Klebsiella spp. (4.3\%) and Enterobacter spp. (1.8\%), (Table 1). Only $4.3 \%$ of patients were treated empirically with CMS.

75 patients $(46 \%)$ developed nephrotoxicity attributable to colistin treatment, although only 14 patients $(8.6 \%)$ discontinued treatment for this reason. The median onset time of nephrotoxicity after initiation of CMS treatment was 7 days (IQR: 4-11).

Therefore, the reasons for discontinuation of CMS treatment were cure $(57.7 \%)$ followed by patient's death $(17.8 \%)$, and treatment adjustment by isolated microorganism (10.4\%), among others (Table1).

2. Risk factor associated with nephrotoxicity

In the bivariate analysis of factors associated with the incidence of nephrotoxicity, the following were found: age (70.4 years vs 62.2 years, $p=0.003$ ), Charlson Index ( 2 vs 1.5, $p=0.012$ ), Basal Glomerular Filtration Rate $(82.7 \mathrm{ml} / \mathrm{min} / 1.73 \mathrm{~m}$ vs $105.7 \mathrm{ml} / \mathrm{min} / 1.73 \mathrm{~m}, \mathrm{p}<0.001)$ and hemoglobin levels ( $9.5 \mathrm{vs} 10.3$, 
$p<0.001)$. Patients were also stratified according to baseline clearance, and those with baseline clearance below $75 \mathrm{ml} / \mathrm{min} / 1.73 \mathrm{~m}$ had a higher incidence rate of nephrotoxicity $(68 \%, \mathrm{p}=0.041)$ (Table 2 ). Furthermore, in this group of patients, the source of infection was other than respiratory $(70.7 \%$ vs $47.7 \%$, $p=0.003$ ). The duration of treatment with CMS was longer ( 12 days vs 9 days, $p=0.009)$ and consequently the cumulative dose was higher (78 MU vs $60 \mathrm{MU}, \mathrm{p}=0.013$ ). Due to nephrotoxicity, a higher percentage of dose adjustment was performed in these patients $(37.3 \%$ vs $20.5 \%, p=0.017)$. In addition, in patients with nephrotoxicity, the rate of appropriate prescription was lower $(9.3 \%$ vs $20.5 \%, p=0.050)$ Table1.

Regarding clinical outcomes, the higher mortality rate corresponded to patients with nephrotoxicity ( $44.0 \%$ vs $27.3 \%, p=0.027)$, lowest cure rate $(48.0 \%$ vs $65.9 \% \mathrm{p}=0.022)$, and shorter hospital stay (45 days vs 52 days; $p=0.049)$. Table 3 .

In the multivariate analysis, the risk factors that independently were associated with nephrotoxicity were Charlson Index (OR 1.29, 95\% Cl 1.02-1.62; $\mathrm{p}=0.032)$; admission to the ICU (OR 4.25, 95\% Cl 1.63-11.07, $\mathrm{p}=0.003$ ) and cumulative dose per patient (OR 1.03, 95\% $\mathrm{Cl} 1.01-1.05, \mathrm{p}=0.003)$. However, high creatinine clarence (OR $0.95,95 \% \mathrm{Cl} 0.93-0.97$ ), respiratory infection (OR $0.16,95 \% \mathrm{Cl} 0.06-0.39$ ) and appropriate CMS prescription (OR $0.29,95 \% \mathrm{Cl} 0.08-1.03, \mathrm{p}=0.056)$ were found to be protective factors against the onset of nephrotoxicity. Table 4.

3. Risk factor associated with in-hospital mortality

To assess the impact of nephrotoxicity on mortality, a univariate analysis was carried out. Risk factors associated with mortality were identified, including: age (OR $1.02,95 \% \mathrm{Cl} 1.0-1.05, p=0.048)$ and nephrotoxicity (OR $2.09,95 \% \mathrm{Cl} 1.09-4.03, p=0.027)$; on the other hand, serum hemoglobin proved to be a protective factor $(\mathrm{OR} 0.83,95 \% \mathrm{Cl} 0.69-0.99, \mathrm{p}=0.038)$.

Furthermore, mortality rate was compared according to the onset of nephrotoxicity at 7 days or later and statistically significant difference was found $(\mathrm{OR} 2.95,95 \% \mathrm{Cl} 1.14-7.63 ; \mathrm{p}=0.024)$. Patients who developed nephrotoxicity within the first 7 days after initiation of treatment have a higher mortality rate (57.5\% vs 31.4\%) (Table 6).

However, in the multivariate analysis risk factors associated with mortality were male sex (OR $2.43,95 \% \mathrm{Cl}$ 1.06-5.56, $\mathrm{p}=0.035)$; age (OR 1.03, 95\% Cl 1.01-1.05, $\mathrm{p}=0.043)$ and higher maintenance doses (OR 1.21, $95 \% \mathrm{Cl} 1.03-1.43, \mathrm{p}=0.023)$. Nephrotoxicity due to CMS treatment was not related to mortality (OR 1.42, $95 \% \mathrm{Cl} 0.68-2.99, \mathrm{p}=0.351)$.

Otherwise, serum hemoglobin levels and length of hospital stay were protective factors against mortality (OR $0.76,95 \% \mathrm{Cl} 0.63-0.92, \mathrm{p}=0.005$ and $\mathrm{OR} 0.99,95 \% \mathrm{Cl} 0.98-1.00, \mathrm{p}=0.046$ respectively) Table 5.

\section{Discussion}

CMS is a drug that was rarely used until recently, but with the emerging rise of multidrug-resistant microorganisms as carbapenemase-producing Enterobacteriaceae and the lack of therapeutic arsenal, it 
has been reintroduced into clinical practice.

This study shows impact of dosage and duration on the incidence of nephrotoxicity. Nephrotoxicity due to treatment developed in almost half of the patients, taking into account that only in one third of them the dosage was adjusted according to variations in renal clearance rates and that the loading dose was used in only one quarter. These results may suggest that the issue is not colistin itself but its inappropriate use

Patients who did not develop nephrotoxicity during treatment had a higher percentage of appropriate CMS prescriptions (20.5\% vs. $9.3 \%, p=0.05)$. On the other hand, longer treatments with CMS obviously increased the incidence of renal function alteration (9 days vs 12 days, $p=0.009$ ). This may be due to CMS delay in reaching steady state for about 48 hours without the loading dosage which may, therefore, delay the onset of clinical efficacy of the drug, increasing treatment duration and worsening the clinical outcomes of the patients ${ }^{9}$.

In a retrospective study including 115 patients treated with CMS, nephrotoxicity appeared in $14 \%$ of them. The dosage of CMS was adjusted to each patient's renal clearance and all patients undergoing continuous renal replacement therapy were excluded ${ }^{18}$. Nevertheless, therapeutic success was achieved in half of them, similar to the results obtained in our study. Although, in other studies, clinical cure data were comparatively higher - $82.1 \%$ - which could be due to the reduced number of patients analyzed, only $28.1 \% 9$.

Multidrug-resistant $A$. baumannii was the most frequent microorganism treated with CMS and, in more than half of the cases, CMS was administered in combination therapy -mostly with carbapenems and tigecycline- with poor results. This fact supports the idea of the need of increasing research for new antibiotics, in addition to faster approval by the evaluating agencies of drugs that already exist and are more effective, less toxic and easier to use than CMS, such as Cefiderocol or Aztreonam/avibactam.

Moreover, in the empirical treatment of infections caused by multidrug-resistant bacteria in critically ill or severe patients we believe that combination therapy should be the strategy to be employed ${ }^{19}$. In contrast to this opinion, there are some studies such as the one carried out in patients with infections caused by $A$. baumanii in which CMS was compared in monotherapy and in combination therapy with tigecycline at standard dosage ${ }^{20}$. These studies found that patients receiving the association of Tigecycline with a high dosage of CMS did not present the expected decrease in crude mortality. It should be considered that in this study only bacteremias were analyzed, mostly with respiratory foci and with a dosage of tigecycline of $50 \mathrm{mg} / 12 \mathrm{~h}$. For these indications, it is known that tigecycline does not improve clinical outcomes ${ }^{21}$. This may be due to two reasons: firstly, the dosage of Tigecycline used in respiratory infections has shown to be insufficient and led to a higher failure rate in a clinical trial in which it was compared to Imipenem-cilastatin ${ }^{22}$; secondly, given its pharmacokinetics and pharmacodynamics, it is not recommended for use in bacteremia ${ }^{23}$. In our study, there were only $17 \%$ of bacteremias and most of 
the patients with respiratory infections treated with tigecycline received high dosage - a $200 \mathrm{mg}$ loading dose followed by $100 \mathrm{mg} / 12 \mathrm{~h}$.

Another study, in which clinical outcomes were analyzed after treatment of $A$. baumanii infections, showed better results in the group treated with CMS monotherapy than in combination with meropenem ${ }^{16}$. In this study, the mortality rate was lower with CMS-resistant isolates due to loss of virulence compared to CMS-sensitive strains. We did not find a statistically significant relationship between combined treatment and mortality. However, patients treated with three antibiotics active against gram-negative bacteria had a higher incidence of nephrotoxicity. In addition, it should be considered the presence of heteroresistance in strains apparently sensitive to colistin, which may become resistant during treatment ${ }^{24}$. In order to avoid this and to ensure the effectiveness of colistin during treatment, it is crucial not to use CMS in monotherapy and at low dosages.

Hence, to avoid antibiotic pressure and selection of multi-resistant microorganisms, it is necessary to use colistin in combination therapy; however, and more importantly, in terms of clinical results, it is not clear which association is better in case of infections caused by A.baumanii, especially when the second antibiotic is not active $\mathrm{e}^{25,26}$.

It has been shown that nephrotoxicity is related to the accumulated dosage of CMS per patient ${ }^{27}$, which is also the result of our study. This could be explained by the chemical structure of the drug and its mechanism of action. Despite the high incidence of serum creatinine alteration (46\%), treatment was interrupted in only $8.6 \%$ of the patients. However, in another retrospective study with a cohort of patients similar to ours, the incidence of nephrotoxicity was $60.4 \%(95 \% \mathrm{Cl}, 50.8 \%-69.2 \%)^{28}$. Furthermore, it was previously found that low hematocrit levels have been associated with nephrotoxicity, although it is difficult to explain the relationship in critically ill patients, often with fluid overload ${ }^{11}$.

Our study has some limitations. It has a retrospective design without a control group and was performed in only one medical center. Serum concentrations of CMS were not measured to verify the correlation between CMS serum levels and increased creatinine levels in blood. Moreover, daily creatinine monitoring in patients on CMS treatment is not common.

Nevertheless, we would like to underline that only a very small number of hospitals in Spain have monitoring of serum CMS levels in order to optimize pk/pd parameters and improve clinical outcomes. Monitoring CMS with creatinine levels alone is not an optimal strategy for a wide range of reasons.

In terms of strengths, this study includes a larger number of patients than those published to date, and supports the existing evidence on the use of this drug and its impact on renal function.

In conclusion, it was shown once again that CMS is a drug with a high incidence of nephrotoxicity. Its complex management, administering the loading dose and monitoring creatinine at least every 48 hours, with consequent adjustment of the maintenance dosage, leads to a high percentage of inappropriate use. Nowadays, it remains though one of the few treatment alternatives for life-threatening infections caused 
by multidrug-resistant gram-negative bacilli. Therefore, we will have to continue using it despite its poor results if the procedures with new antibiotics are not facilitated and more investment is not made in the research of new molecules for these microorganisms.

\section{Declarations}

\section{Authors contributions:}

SSD: conceived and designed the study, collected the data, performed the analysis, wrote the manuscript.

RGF: collected the data, wrote the manuscript.

AJM: critical review of the manuscript

JP: critical review of the manuscript

$\mathrm{CHT}$ : critical review and wrote the paper.

All authors review the manuscript

\section{References}

1. Li, J. et al. Colistin: the re-emerging antibiotic for multidrug-resistant Gram-negative bacterial infections. Lancet Infect. Dis. 6, 589-601 (2006).

2. SJ, W. et al. Self-assembly behavior of colistin and its prodrug colistin methanesulfonate: implications for solution stability and solubilization. J. Phys. Chem. B 114, 4836-4840 (2010).

3. Mohamed, A. F. et al. Application of a loading dose of colistin methanesulfonate in critically ill patients: Population pharmacokinetics, protein binding, and prediction of bacterial kill. Antimicrob. Agents Chemother. 56, 4241-4249 (2012).

4. Plachouras, D. et al. Population Pharmacokinetic Analysis of Colistin Methanesulfonate and Colistin after Intravenous Administration in Critically III Patients with Infections Caused by Gram-Negative Bacteria t. 53, 3430-3436 (2009).

5. Bergen, P. J., Li, J. \& Nation, R. L. Dosing of colistin - Back to basic PK/PD. Curr. Opin. Pharmacol. 11, 464-469 (2011).

6. Zusman, 0. et al. Polymyxin monotherapy or in combination against carbapenem-resistant bacteria: Systematic review and meta-analysis. J. Antimicrob. Chemother. 72, 29-39 (2017).

7. Molina, J., Cordero, E., Palomino, J. \& Pachón, J. Aminogluc??sidos y polimixinas. Enferm. Infecc. Microbiol. Clin. 27, 178-188 (2009).

8. Falagas, M. E., Kasiakou, S. K. \& Saravolatz, L. D. Colistin: The Revival of Polymyxins for the Management of Multidrug-Resistant Gram-Negative Bacterial Infections. Clin. Infect. Dis. 40, 13331341 (2005). 
9. Dalfino, L. et al. High-dose, extended-interval colistin administration in critically ill patients: Is this the right dosing strategy? a preliminary study. Clin. Infect. Dis. 54, 1720-1726 (2012).

10. Chien, H. T., Lin, Y. C., Sheu, C. C., Hsieh, K. P. \& Chang, J. S. Is colistin-associated acute kidney injury clinically important in adults? A systematic review and meta-analysis. International Journal of Antimicrobial Agents 55, (2020).

11. Lee, Y. J. et al. Association between Colistin Dose and Development of Nephrotoxicity. Crit. Care Med. 43, 1187-1193 (2015).

12. Boisson, M., Gregoire, N., Couet, W. \& Mimoz, O. Colistin in critically ill patients. Minerva ... (2013).

13. Nation, R. L. et al. Dosing guidance for intravenous colistin in critically ill patients. Clin. Infect. Dis. 64, 565-571 (2017).

14. Kaddourah, A., Basu, R. K., Bagshaw, S. M. \& Goldstein, S. L. Epidemiology of Acute Kidney Injury in Critically III Children and Young Adults. N. Engl. J. Med. 376, 11-20 (2017).

15. Elham, B. \& Fawzia, A. Colistin resistance in Acinetobacter baumannii isolated from critically ill patients: Clinical characteristics, antimicrobial susceptibility and outcome. Afr. Health Sci. 19, 24002406 (2019).

16. Dickstein, Y. et al. Treatment Outcomes of Colistin- and Carbapenem-resistant Acinetobacter baumannii Infections: An Exploratory Subgroup Analysis of a Randomized Clinical Trial. Clin. Infect. Dis. 69, 769-776 (2019).

17. Khwaja, A. KDIGO clinical practice guidelines for acute kidney injury. Nephron - Clinical Practice 120, c179-c184 (2012).

18. Cheng, C. Y., Sheng, W. H., Wang, J. T., Chen, Y. C. \& Chang, S. C. Safety and efficacy of intravenous colistin (colistin methanesulphonate) for severe multidrug-resistant Gram-negative bacterial infections. Int. J. Antimicrob. Agents 35, 297-300 (2010).

19. Falagas, M. E., Lourida, P., Poulikakos, P., Rafailidis, P. I. \& Tansarli, G. S. Antibiotic treatment of infections due to carbapenem-resistant enterobacteriaceae: Systematic evaluation of the available evidence. Antimicrob. Agents Chemother. 58, 654-663 (2014).

20. Amat, T. et al. The combined use of tigecycline with high-dose colistin might not be associated with higher survival in critically ill patients with bacteraemia due to carbapenem-resistant Acinetobacter baumannii. Clin. Microbiol. Infect. 24, 630-634 (2018).

21. De Pascale, G. et al. High dose tigecycline in critically ill patients with severe infections due to multidrug-resistant bacteria. Crit. Care 18, (2014).

22. Ramirez, J. et al. Randomized phase 2 trial to evaluate the clinical efficacy of two high-dosage tigecycline regimens versus imipenem-cilastatin for treatment of hospital-acquired pneumonia. Antimicrob. Agents Chemother. 57, 1756-1762 (2013).

23. Stein, G. E. \& Babinchak, T. Tigecycline: An update. Diagnostic Microbiology and Infectious Disease 75, 331-336 (2013). 
24. Li, J. et al. Heteroresistance to colistin in multidrug-resistant Acinetobacter baumannii. Antimicrob. Agents Chemother. 50, 2946-2950 (2006).

25. Tsuji, B. T. et al. International Consensus Guidelines for the Optimal Use of the Polymyxins: Endorsed by the American College of Clinical Pharmacy (ACCP), European Society of Clinical Microbiology and Infectious Diseases (ESCMID), Infectious Diseases Society of America (IDS. Pharmacotherapy 39, 10-39 (2019).

26. Paul, M. et al. Colistin alone versus colistin plus meropenem for treatment of severe infections caused by carbapenem-resistant Gram-negative bacteria: an open-label, randomised controlled trial. Lancet Infect. Dis. 18, 391-400 (2018).

27. Falagas, M. E., Fragoulis, K. N., Kasiakou, S. K., Sermaidis, G. J. \& Michalopoulos, A. Nephrotoxicity of intravenous colistin: A prospective evaluation. Int. J. Antimicrob. Agents 26, 504-507 (2005).

28. Akajagbor, D. S. et al. Higher incidence of acute kidney injury with intravenous colistimethate sodium compared with polymyxin b in critically ill patients at a tertiary care medical center. Clin. Infect. Dis. 57, 1300-1303 (2013).

\section{Tables}

Table 1: Characteristics of patients in the study cohort 


\begin{tabular}{|c|c|c|c|c|}
\hline Characteristics of patients & Total(n=163) & $\begin{array}{l}\text { Nephrotoxicity } \\
\text { group } \\
\mathrm{n}=75(46 \%)\end{array}$ & $\begin{array}{l}\text { Non- } \\
\text { nephrotoxicity } \\
\text { group } \\
\mathrm{n}=88(54.0 \%)\end{array}$ & $\mathbf{p}$ \\
\hline Sex,male,n(\%) & $116(71.2)$ & $50(66.7)$ & $65(75.0)$ & 0.242 \\
\hline Age,years,mean(SD) & $65.93 \pm 15.98$ & $70.4 \pm 12.35$ & $62.2 \pm 17.73$ & 0.003 \\
\hline Charlson index score,median(IQR) & $2(1-3)$ & $2(1-4)$ & $1.5(0-3)$ & 0.012 \\
\hline \multicolumn{4}{|l|}{ ICU vs others } & 0.474 \\
\hline $\begin{array}{l}\text { Basal Glomerular Filtration } \\
\text { Rate(eGFR), } \mathrm{ml} / \mathrm{min} / 1.73 \mathrm{~m} \text {, } \\
\text { median(IQR) }\end{array}$ & $\begin{array}{l}92.2(75- \\
113.5)\end{array}$ & $\begin{array}{l}82.7(49.5- \\
98.2)\end{array}$ & $\begin{array}{l}105.7(90.2- \\
122.9)\end{array}$ & $<0.001$ \\
\hline Creatinine basal,mg/dL, mean(SD) & $0.89 \pm 0.78$ & $1.12 \pm 0.91$ & $0.7 \pm 0.61$ & $<0.001$ \\
\hline Albumin,median,mean(SD) & $3.14 \pm 0.75$ & $3.14 \pm 0.83$ & $3.13 \pm 0.68$ & 0.568 \\
\hline Hemoglobin,mean(SD) & $9.91 \pm 2.01$ & $9.45 \pm 1.51$ & $10.31 \pm 2.30$ & $<0.001$ \\
\hline Leucocites,cells $/ \mathrm{ml}{ }^{\star} 10^{3}$, median(IQR) & $\begin{array}{l}10.3(7.0- \\
15.2)\end{array}$ & $9.48(6.7-13.8)$ & 10.9(7.3-15.6) & 0.312 \\
\hline Protein Reactive C, median(IQR) & $\begin{array}{l}119.2(40.5- \\
176.5)\end{array}$ & $\begin{array}{l}122.1(52.2- \\
194.5)\end{array}$ & $\begin{array}{l}102.5(32.1- \\
167.9)\end{array}$ & 0.134 \\
\hline Respiratory tract infections,n(\%) & $68(41.7)$ & $22(29.3)$ & $46(52.3)$ & 0.003 \\
\hline \multicolumn{5}{|l|}{ Others } \\
\hline & $95(58.3)$ & $53(70.7)$ & $42(47.7)$ & \\
\hline Bloodstream infection, n(\%) & $28(17.2)$ & $12(16.0)$ & 16(18.2) & 0.713 \\
\hline Target therapy, n(\%) & 156(95.7) & $71(94.7)$ & $85(96.6)$ & 0.546 \\
\hline Appropriate treatment, n(\%) & 25(15.3) & $7(9.3)$ & 18(20.5) & 0.050 \\
\hline Combination therapy,n(\%) & $105(64.4)$ & $48(64.0)$ & $57(64.8)$ & 0.918 \\
\hline \multicolumn{5}{|l|}{ Number of associated antibiotics: } \\
\hline -with one antimicrobial & & $34(40.5)$ & $50(59.5)$ & 0.031 \\
\hline \multirow[t]{2}{*}{-with two antimicrobials } & $84 / 105(51.5)$ & $14(29.2)$ & $7(12.3)$ & \\
\hline & $21 / 105(12.9)$ & & & \\
\hline
\end{tabular}


Antibiotics used in combined therapy:

Types (\%):

Carbapenems

Tigecycline 33.95

Aminoglycosides

24.0

Fosfomycin

11.95

Fluroquinolones

11.4

Other's beta-lactams

10.1

19.15

Loading dose, $\mathrm{n}(\%)$ 35(24.5)

23(30.7)

18(20.5)

0.134

Maintenance dose,median(IQR)

7.5(6-9)

9(6-9)

$6(6-9)$

0.499

Cumulative dose per patient, median(IQR)

Dose adjustment by eGFR

63(36-108)

78(50-126)

60(36-90)

0.013

Duration of CMS therapy,median(IQR)

$46(28.2)$

28(37.3)

18(20.5)

0.017

Microorganisms, $\mathrm{n}(\%)$

Acinetobacter spp.

118(72.4)

57(76.0)

61(69.3)

0.125

Pseudomonas spp.

32(19.6)

9(12.0)

23(26.1)

Klebsiella spp.

$7(4.3)$

$5(6.7)$

2(2.3)

Enterobacterspp.

$3(1.8)$

2(2.7)

$1(1.1)$

Negative results

$3(1.8)$

2(2.7)

$1(1.1$

Reasons for CMS discontinuation, $\mathrm{n}(\%)$ :

End of the treatment

Nephrotoxicity

Deterioration

Death

Adjustment of antibiotics

Allergic reaction

$\begin{array}{lll}94(57.7) & 36(48.0) & 58(65.9) \\ 14(8.6) & 14(18.7) & 0(0.0) \\ 7(4.3) & 4(5.3) & 3(3.4) \\ 29(17.8) & 15(20.0) & 14(15.9) \\ 17(10.4) & 6(8.0) & 11(12.5) \\ 2(1.2) & 0(0.0) & 2(2.3)\end{array}$


Table 2: Incidence of nephrotoxicity stratified by baseline creatinine clearance

\begin{tabular}{|lllll|}
\hline & \multicolumn{4}{l}{ Baseline Glomerular Filtration Rate(eGFR), $\mathrm{ml} / \mathrm{min} / 1.73 \mathrm{~m}$} \\
\hline & $\leq 75$ & $75.1-92$ & $92.1-113.5$ & $\geq 113.6$ \\
\hline Incidence of Nephrotoxicity,n(\%) & $28(68.3) *$ & $25(61.0)$ & $15(36.6)$ & $7(17.5)$ \\
\hline
\end{tabular}

$*_{p}=0,041$

Table 3: Clinical outcomes of patients treated with CMS

\begin{tabular}{|llllll|}
\hline $\begin{array}{l}\text { Characteristics of } \\
\text { patients }\end{array}$ & Total(n=163) & $\begin{array}{l}\text { Nephrotoxicity } \\
\text { group } \\
\mathrm{n=75(46 \% )}\end{array}$ & $\begin{array}{l}\text { Non- } \\
\text { nephrotoxicity } \\
\text { group } \\
\mathrm{n=88(54.0)}\end{array}$ & $\begin{array}{l}\text { OR, } \\
\mathbf{9 5 \%}\end{array}$ & $\mathrm{p}$ \\
\hline $\begin{array}{l}\text { Duration hospital } \\
\text { stay,days,median(IQR) }\end{array}$ & $48(29-94)$ & $45(29-76)$ & $52(27-106)$ & $\begin{array}{l}0.99(0.98- \\
1.00)\end{array}$ & 0.049 \\
\hline Clinical success, $\mathrm{n}(\%)$ & $94(57.7)$ & $36(48.0)$ & $58(65.9)$ & $\begin{array}{l}0.48(0.25- \\
0.89)\end{array}$ & 0.022 \\
\hline In-hospital mortality, $\mathrm{n}(\%)$ & $57(35.0)$ & $33(44.0)$ & $24(27.3)$ & $\begin{array}{l}2.09(1.09- \\
4.03)\end{array}$ & 0.027 \\
\hline
\end{tabular}

Table 4: Univariable and multivariable analysis of risk factors for nephrotoxicity 


\begin{tabular}{|c|c|c|c|c|}
\hline \multirow[t]{2}{*}{ Variable } & \multicolumn{2}{|l|}{ Univariable } & \multicolumn{2}{|c|}{ Multivariable } \\
\hline & OR $(95 \% \mathrm{Cl})$ & p & $\begin{array}{l}\text { OR } \\
(95 \% \mathrm{Cl})\end{array}$ & $\mathbf{p}$ \\
\hline Sex,male,n(\%) & $\begin{array}{l}0.67(0.34- \\
1.32)\end{array}$ & 0.243 & & \\
\hline Age,years,mean(SD) & $\begin{array}{l}1.04(1.01- \\
1.06)\end{array}$ & 0.002 & & \\
\hline Charlson index score,median(IQR) & $\begin{array}{l}1.19(1.01- \\
1.34)\end{array}$ & 0.033 & $\begin{array}{l}1.29(1.02- \\
1.62)\end{array}$ & 0.032 \\
\hline $\begin{array}{l}\text { Setting: } \\
\text { ICU vs others }\end{array}$ & $\begin{array}{l}1.26(0.67- \\
2.34)\end{array}$ & 0.474 & $\begin{array}{l}4.25(1.63- \\
11.07)\end{array}$ & 0.003 \\
\hline $\begin{array}{l}\text { Baseline Glomerular Filtration Rate(eGFR), } \\
\mathrm{ml} / \mathrm{min} / 1.73 \mathrm{~m} \text {, median(IQR) }\end{array}$ & $\begin{array}{l}0.97(0.96- \\
0.98)\end{array}$ & $<0.001$ & $\begin{array}{l}0.95(0.93- \\
0.97)\end{array}$ & $<0.001$ \\
\hline Creatinine basal,mg/dL, median(IQR) & $\begin{array}{l}2.9(1.39- \\
6.02)\end{array}$ & 0.004 & & \\
\hline Albumin,median(IQR) & $\begin{array}{l}1.01(0.66- \\
1.52)\end{array}$ & 0.982 & & \\
\hline Hemoglobin,mean(SD) & $\begin{array}{l}0.79(0.66- \\
0.94)\end{array}$ & 0.008 & & \\
\hline Leucocites,cells $/ \mathrm{ml} * 10^{3}$, median(IQR) & $\begin{array}{l}1.01(0.98- \\
1.04)\end{array}$ & 0.422 & & \\
\hline Protein Reactive C, median(IQR) & $\begin{array}{l}1.00(0.99- \\
1.002)\end{array}$ & 0.858 & & \\
\hline Respiratory tract infections,n(\%) & $\begin{array}{l}0.38(0.20- \\
0.72)\end{array}$ & 0.003 & $\begin{array}{l}0.16(0.06- \\
0.39)\end{array}$ & $<0.001$ \\
\hline 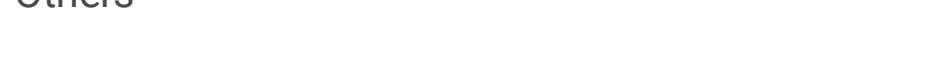 & Ref. & & & \\
\hline Bloodstream infection, n(\%) & $\begin{array}{l}1.16(0.51- \\
2.65)\end{array}$ & 0.713 & & \\
\hline Target therapy, n(\%) & $\begin{array}{l}0.63(0.14- \\
2.89)\end{array}$ & 0.549 & & \\
\hline Appropriate treatment, $\mathrm{n}(\%)$ & $\begin{array}{l}0.40(0.16- \\
1.02)\end{array}$ & 0.055 & $\begin{array}{l}0.29(0.08- \\
1.03)\end{array}$ & 0.056 \\
\hline Combination therapy,n(\%) & $\begin{array}{l}0.97(0.51- \\
1.84)\end{array}$ & 0.918 & & \\
\hline 2antibiotics vs gram-negative associated to CMS & $\begin{array}{l}2.66(1.01- \\
6.98)\end{array}$ & 0.048 & & \\
\hline Loading dose, n(\%) & $\begin{array}{l}1.72(0.84- \\
3.51)\end{array}$ & 0.136 & & \\
\hline
\end{tabular}




\begin{tabular}{|c|c|c|c|c|}
\hline Maintenance dose,median(IQR) & $\begin{array}{l}1.03(0.89- \\
1.18)\end{array}$ & 0.703 & & \\
\hline Cumulative dose per patient,median(IQR) & $\begin{array}{l}1.01(1.00- \\
1.011)\end{array}$ & 0.043 & $\begin{array}{l}1.03(1.01- \\
1.05)\end{array}$ & 0.003 \\
\hline Mantenance dose ajustment by eGFR & $\begin{array}{l}2.32(1.15- \\
4.66)\end{array}$ & 0.018 & & \\
\hline Duration of CMS therapy,median(IQR) & $\begin{array}{l}1.06(1.01- \\
1.11)\end{array}$ & 0.025 & $\begin{array}{l}0.88(0.76- \\
1.023)\end{array}$ & 0.100 \\
\hline Microorganisms, n(\%) & \multirow[t]{3}{*}{$\begin{array}{l}1.40(0.69- \\
2.81)\end{array}$} & \multirow[t]{3}{*}{0.343} & & \\
\hline Acinetobacter spp. & & & & \\
\hline Others & & & & \\
\hline
\end{tabular}

Table 5: Multivariable analysis for independent risk factors for in-hospital mortality.

\begin{tabular}{|llll|}
\hline & OR & $95 \% \mathrm{Cl}$ & P-value \\
\hline Sex,male & 2.43 & $1.06-5.56$ & 0.035 \\
\hline Age & 1.03 & $1.01-1.05$ & 0.043 \\
\hline Hemoglobin & 0.76 & $0.63-0.92$ & 0.005 \\
\hline Maintenance dose CMS & 1.21 & $1.03-1.43$ & 0.023 \\
Duration hospital stay & 0.99 & $0.98-1.00$ & 0.046 \\
\hline Nephrotoxicity & 1.42 & $0.68-2.99$ & 0.351 \\
\hline
\end{tabular}

Table 6: Rate of in-hospital mortality depending on the onset of nephrotoxicity

\begin{tabular}{|c|c|c|c|c|c|}
\hline & Total(n=163) & $\begin{array}{l}\text { Nephrotoxicity onset } \\
\leq 7 \text { days } \\
(n=40)\end{array}$ & $\begin{array}{l}\text { Nephrotoxicity } \\
\text { onset } \\
>7 \text { days } \\
(n=35)\end{array}$ & OR, 95\%IC & p \\
\hline $\begin{array}{l}\text { In-hospital } \\
\text { mortality, n(\%) }\end{array}$ & $33(44.0)$ & $23(57.5)$ & 11(31.4) & $\begin{array}{l}2.95(1.14- \\
7.63)\end{array}$ & 0.024 \\
\hline
\end{tabular}

\section{Supplementary Files}


This is a list of supplementary files associated with this preprint. Click to download.

- CMSnov21d1.xlsx

- supplementarymaterial.docx 